\title{
Mini-Gastric Bypass for Bariatric Surgery Increasing Worldwide
}

Deitel $\mathbf{M}^{1 *}$, Hargroder $\mathbf{D}^{2}$ and Peraglie $\mathbf{C}^{3}$

${ }^{1}$ Director Mini-Gastric Bypass-One Anastomosis Gastric Bypass Club, Canada

${ }^{2}$ Department of Surgery, Mercy Hospitals, USA

${ }^{3}$ Department of Surgery, Heart of Florida Regional Medical Center, USA

*Corresponding author: Deitel M, Director MiniGastric Bypass-One Anastomosis Gastric Bypass Club, Canada; Email: book@obesitysurgery.com

Received: November 08, 2016; Accepted: December 08, 2016; Published: December 12, 2016

\begin{abstract}
Introduction: Mini-Gastric Bypass (MGB) originated in 1997 as a simple, rapid and mainly malabsorptive bariatric operation; it is now increasing rapidly.
\end{abstract}

Methods: History, technique, variations and world literature are reviewed.

Results: Reports now find the MGB to be a superior operation with respect to safety, short learning curve, resolution of co-morbidities (especially diabetes), durable weight loss and ease of revision or reversal.

Conclusion: The authors regard MGB as a very favorable operation and present a review.

Keywords: Mini-gastric bypass; Surgical technique; One-anastomosis gastric bypass; Diabetes; Quality of life; Weight loss

\section{Introduction}

Mini-Gastric Bypass (MGB or Malabsorptive Gastric Bypass) was devised by Robert Rutledge in USA in 1997. As a trauma surgeon, he was faced with an abdominal gun-shot wound where a duodenal exclusion with a Billroth II anastomosis was an appropriate reconstruction. This was the inspiration that led Rutledge to the MGB on consenting bariatric patients, constructing a long lesser curvature channel which prevents reflux $[1,2]$. In the USA, there was some skepticism against the MGB.

In 2001, the first author (MD) spent 15 days as a guest in Dr. Rutledge's O.R. and pre- and post-operative clinic, inspecting his substantial follow-up. The MGB has since increased throughout the world [3-14]. With the decrease in gastric banding, the MGB in 2015 became the third most common bariatric operation internationally [15].

\section{Technique of MGB}

The laparoscopic MGB (Figure 1) has two components: 1) a lessercurvature long gastric pouch, serving as a slightly restrictive conduit; 2) a $180-200 \mathrm{~cm}$ jejunal bypass with a wide antecolic Gastrojejunal (GJ) anastomosis, which leads to carbohydrate and especially fat malabsorption.

\section{Creation of the pouch}

After making a window into lesser sac, the lesser curvature of the stomach is stapler-divided at a right-angle $2-3 \mathrm{~cm}$ distal to the crow's foot. Next, a 28-38 Fr bougie is passed by the anesthesiologist and the stomach is then stapler-divided cephalad parallel to lesser curvature. At the Gastro-Esophageal (GE) junction, the surgeon divides the gastric sleeve a few $\mathrm{mm}$ lateral to the angle of His; the cardia and left crus are explicitly avoided and not dissected, unlike in the Laparoscopic Sleeve Gastrectomy (LSG) [16-18].

Thus, a low-pressure gastric conduit is constructed [19], unlike the high-pressure conduit of the LSG [20].

\section{Creation of the malabsorptive jejunal bypass}

Attention is turned to the left gutter. The greater omentum is retracted medially to identify ligament of Treitz. The jejunum is run to $200 \mathrm{~cm}$ (Hargroder) or $180 \mathrm{~cm}$ (Peraglie) distal to Treitz' ligament. Hargroder uses the width of his paddle retractor $\left(3.5^{\prime \prime}, 8.75 \mathrm{~cm}\right)$ to measure the $200 \mathrm{~cm}$. Peraglie traces the jejunum with $2.5 \mathrm{~cm}$ grasps hand-over-hand to $180 \mathrm{~cm}$.

In super-obese patients, $250 \mathrm{~cm}$ of proximal jejunum may be bypassed. However, with lower BMI with co-morbidities such as diabetes, a shorter jejunal limb $(150 \mathrm{~cm})$ may be bypassed [21-24].

At the selected site, the tip or adjacent posterior wall of the gastric pouch is anastomosed antecolic to the jejunum (can be fully-stapled, hand-sewn or hybrid-end-to-side or side-to-side), constructing a wide anastomosis under easy view. Attention is given to avoid a twist at the GJ anastomosis. The GJ anastomosis should be at least $300 \mathrm{~cm}$ proximal to the ileocecal valve, to avoid protein malnutrition.

If a Hiatal Hernia $(\mathrm{HH})$ is present, it is not dissected and repaired at the time of the MGB operation. If needed, $\mathrm{HH}$ repair can be performed 12-18 months later. Experience has shown that the MGB is very effective in resolving GE Reflux Disease (GERD). This is due to traction that the GJ provides on the gastric pouch, reducing the cardia into the abdomen, plus the decreasing post-operative intraabdominal obesity.

However, if a large $\mathrm{HH}$ is present with adherence to the gastric fundus, it is dissected and repaired at the time of MGB; otherwise, a large bulbous fundus could be left.

The non-obstructed pouch allows slight restriction but adequate oral intake, accompanied by fat/carbohydrate malabsorption. Because the patient avoids carbohydrate which could produce rapid dumping, the intake has mainly fat malabsorption. The pouch in the MGB develops minimal dilatation, because there is no outlet narrowing by a stoma or pylorus [19]. There is slight increase in the number of stools per day (generally from 1 to 2 ). 


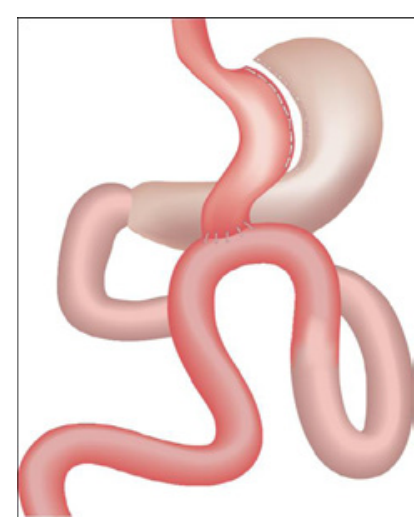

Figure 1: MGB created by horizontal division distal to crow's foot and then vertical division upwards $(\sim 18 \mathrm{~cm})$ to the left of the angle of His. A $3 \mathrm{~cm}$ wide antecolic gastrojejunostomy is performed $200 \mathrm{~cm}$ (varied with BMI) distal to Treitz' ligament, providing malabsorption.

\section{Modifications of the MGB}

Prasad and Bhandari perform the MGB using robotics, which is very feasible $[25,26]$.

Greco and Tacchino have performed $>1,300$ MGBs by SingleIncision Laparoscopic Surgery (SILS) [27]. They subsequently reported their modification of the MGB called the "ileal food diversion" [28]; they construct a larger gastric pouch, turning the staple-line toward the greater curvature leaving the fundus in place and perform the gastro-intestinal anastomosis $300 \mathrm{~cm}$ proximal to ileocecal valve, leaving a $300 \mathrm{~cm}$ common channel. This modification results in a "non-restrictive" MGB that functions like a Scopinaro biliopancreatic diversion.

After standard MGB, if ever necessary for inadequate or excess weight loss, the MGB can be modified by moving the GJ anastomosis distally or proximally, as a brief simple procedure [29]. The MGB can also be easily reversed in rare cases of intractable hypoalbuminemia or significant excess weight loss; reversal entails stapler-division along the GJ anastomosis (carefully inspecting the jejunal side), linear anastomosis of the gastric pouch to the matched bypassed stomach and closing the defect at the bottom of the gastric pouch with running suture [24].

\section{The One-Anastomosis Gastric Bypass (OAGB)}

This paper deals with the MGB. However, in 2002, after reading Rutledge's initial paper showing simplicity and safety of the MGB [1], Miguel Carbajo and Manuel Garciacaballero in Spain (who had been performing the RYGB for $>10$ years) began their variant of the MGBthe OAGB (or BAGUA-Bypass Gastrico de Una Anastomosis) (Figure 2 ), which has a similar malabsorptive component [30]. Because of suspicion by others of potential reflux and cancer, they designed a MGB variant with a side-to-side anastomosis of the biliopancreatic limb to the gastric pouch (rising on the remnant stomach), to facilitate emptying of biliopancreatic juice toward the efferent limb and thus prevent reflux [31]. The common limb (distal to the bypass) must always be $\geq 300 \mathrm{~cm}$, to prevent malabsorption. In $>2,500$ patients, Carbajo has not needed to revise any OAGB for reflux.

Thousands of OAGBs have been performed in Spain and Mexico and it currently represents $\sim 23 \%$ of the single anastomosis gastric

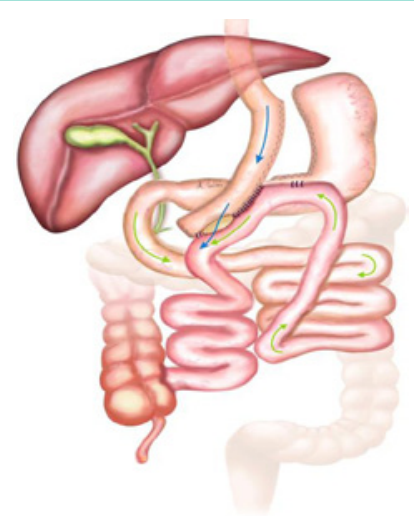

Figure 2: OAGB with gastric pouch $(\sim 15 \mathrm{~cm})$ and an antecolic $2.5 \mathrm{~cm}$ latero-lateral anastomosis between pouch and afferent jejunal loop which is suspended above the anastomosis by an initial continuous suture which secures the loop to the gastric pouch's staple-line, with final fixation of the loop's apex to the bypassed stomach. Biliopancreatic limb averages 250-350 $\mathrm{cm}$ (diagram by Arturo Valdes Alvarez of Saltillo, Mexico).

bypasses. The MGB itself, with the long gastric conduit, has a GE bile reflux problem in $<1.0 \%$ [14] (which may be treated conservatively or by Braun jejunojejunostomy or RYGB). There has been no reported study comparing the OAGB to the MGB with respect to GE reflux. The OAGB takes slightly longer to perform and is slightly more difficult to reverse than the MGB.

\section{Revision to MGB for Lap-Band or LSG Faillure}

After the lap-band or LSG, the MGB is being used as a salvage for weight regain $[4,32]$. In long-term follow-up after LSG, sleeve dilatation and weight regain are frequently found [33]. Also, GE reflux may be troublesome in $>30 \%$ of LSG patients [34].

In revision of $L S G$ to $M G B$, the surgeon must not construct a short gastric pouch (like the small pouch of the RYGB). A short high gastric pouch with bile near esophagus could lead to bile reflux esophagitis, like after the old Mason horizontal loop gastric bypass [35]. For the MGB, a long gastric conduit must be constructed to below crow's foot.

\section{Discussion}

In 2014, a consensus conference of MGB surgeons was held at IFSO Montreal [36], under the leadership of Pradeep Chowbey (President of OSSI, Past President of IFSO), Jean-Marc Chevallier (President of SOFCO), Robert Rutledge, K.S. Kular and M. Deitel. A SurveyMonkey ${ }^{\circ}$ questionnaire was filled out by 73 experienced MGB-OAGB surgeons, who reported prior experience with the other operations-RYGB, banding and LSG. This is an academic group who carefully record their data. The survey identified 24,983 MGBs, with average pre-operative BMI 46.1 (range 35-63) [36]. Mean operating time was 60.7 minutes (range 35-127). Average hospital stay was 3 days (range 1-5) and decreased with experience. Leak was reported in $0.03 \%-6$ patients (usually at the GJ), which is less than the troublesome proximal leaks following LSG [18]. Patients were usually ambulatory a few hours after surgery. Post-operative bleeding was reported in 7 patients $(0.035 \%)$ and appears to be avoided by holding the stapler compressed for $>30$ seconds before firing. With hypertension, it may be advisable to reinforce the staple-line. 
It was found that after MGB, EWL at 1 year was $76 \%, 2$ years $85 \%$, 3 years $78 \%$, 4 years $75 \%, 5$ years $70 \%$, later $69 \%$. The 30 -day mortality was very low- $0.2 \%$. Many of the MGB patients were high-risk.

In USA, the second author of this paper (DEH) has had no operative deaths (i.e. within 30 days) in 1,450 patients over 13 years of MGB; the third author (CP) has had no operative deaths out of 1,800 MGBs over 13 years. Both surgeons were trained by Rutledge. There have been deaths of patients for other reasons in later years. Dr. Rutledge with 6,385 MGBs has had three operative deaths-the last in 2004. Peraglie found no deaths in his super-obese patients [23] and those age $>60$ [37].

GE reflux was found pre-operatively in $15.3 \pm 14.2 \%$ (SD) and post-operatively in $4.6 \pm 14.2 \%$ [36], i.e. GERD improved after the MGB, as demonstrated by Tolone [19]. About $1.5 \%$ of patients noticed bilious vomiting once every 3 months. The underlying cause may be an ulcer or a short pouch. With the long conduit, it was rare for a Braun jejuno-jejunostomy or RYGB to become necessary for bile reflux (0.1\%). Marginal ulcers were reported in $1.6 \pm 1.8 \%$ (range $0-5)$, which is slightly less than after RYGB [38]. Bowel obstruction due to internal hernia was not seen in most practices.

If GE bile reflux does occur, patients should be questioned about smoking and NSAIDs (which are prohibited), eating late at night and lots of fried foods [24]. If true bile reflux does develop, it may be managed with either initial medical therapy or surgical therapy with addition of a Braun enteroenterostomy (ensuring $300 \mathrm{~cm}$ of common limb distally) or conversion to RYGB. It is noted after MGB (as after RYGB) that alcohol is absorbed fairly rapidly. If persisting dyspepsia occurs, H. Pylori or pouch kinking should be ruled out.

H. Pylori (HP) stool antigen or breath test is checked preoperatively and treated if positive. HP is eradicated with helikit control before surgery. However, Rutledge has found that re-infection with HP may negate the value of pre-operative eradication therapy.

\section{Intake requirements}

If there is indigestion, a Proton Pump Inhibitor (PPI) is prescribed. A PPI is important in treating marginal ulcer, as is eradication of $H$. Pylori if present.

After MGB, supplements consist of multi-vitamins, calcium (preferably dairy or calcium citrate), yoghurt; vitamin $\mathrm{D}_{3} 1,000$ IU 2-3 times daily and an intestinally-absorbed iron supplement (Proferrin ${ }^{\circ}$-heme intestinal peptides). The duodenum where iron absorption normally occurs is bypassed in the MGB (as in the RYGB). Thus, in $5 \%$ of menstruating women, iron deficiency develops and requires increased oral iron or rarely IM or IV iron [39]. If $B_{12}$ levels fall, replacement by sublingual crystalline $B_{12}$ or injection becomes necessary.

Fruits and salads are well tolerated. Foods containing protein are important, e.g. meats, seafood, nuts and dairy. Patients prevent "dumping" (weakness, sweating and diarrhea) by avoiding highglycemic foods. No intractable hypoglycemia has been reported. Fried, greasy, fatty foods cause cramps and diarrhea (steatorrhea) and are thus avoided.

Vegetarians must take protein-legumes (lentils, beans, chick peas, peanuts and quinoa), yoghurt, milk, soy (tofu) or whey protein, bran, brown rice, etc. Vegetables have incomplete protein, but inclusion of multiple vegetables provides total amino acid requirements. In vegetarians and the elderly, it is advisable to bypass less than $200 \mathrm{~cm}$ of jejunum to avoid hypoalbuminemia [22].

\section{Fear of development of cancer}

After RYGB, lap-band or LSG, carcinoma of the gastric pouch and lower esophagus was reported in 46 patients [40-42]. After LSG, Barrett's esophagus may occur [43]. After MGB, no carcinoma in the gastric pouch or esophagus has been reported. However, in the Far East where the incidence of gastric carcinoma remains high, one gastric carcinoma in Taiwan 9 years after MGB has been reported in the bypassed stomach (but not in the pouch) [44]. Although some workers have compared the MGB to the Billroth II operation performed for peptic ulcer and cancer for 100 years, studies for development of gastric carcinoma after the Billroth II found a decreased incidence [45-47], even though H. Pylori was unknown and thus untreated. Furthermore, after performing $>1,000$ Vagotomy and Pyloroplasties (V\&P) by the first author (MD) in the 1960s-70s for then-prevalent duodenal ulcer (with post-operative bile in the distal stomach), no gastric carcinoma has developed.

There was also fear of development of gastric cancer because of effects of bile and irritants on the rat's stomach. However, Frantz [48] showed that bile led to hyperplasia and neoplasia in the proximal two-thirds of the unique rodent's stomach (which is squamous-cell), but not in the distal glandular third (which corresponds to the human stomach).

\section{Comparison with other bariatric operations}

After LSG [32] and RYGB [49-51], weight regain has been found in the long-term. Comparative studies have documented more durable weight loss after the MGB [3,13,22,52-55]. Also, better quality of life has been found after MGB [56,57]. Regarding diabetes type 2, Lee reported greater elevation of GLP-1 after MGB than after RYGB [55].

Diabetes, hypertension and lipid abnormalities have shown superior remission after MGB $[58,59]$. Diabetes has resolved in 70$94 \%[22,60,61]$. Kular found in diabetic patients with BMI $<35$ that $\mathrm{HbAlc}$ at 7 years after MGB was $5.7 \pm 1.8 \%$ [62]; earlier intervention resulted in higher remission rates. In the Indian population, comorbidities of the metabolic syndrome often present at BMI 27. About 700 Canadians of Indian descent with metabolic syndrome (especially type 2 diabetes) have undergone MGB in India, with excellent resolution.

After the Spanish OAGB (BAGUA), the same resolution of type 2 diabetes and other co-morbidities has been found $[63,64]$, including in the massively obese adolescent [65].

\section{Conclusion}

MGB has been fairly rapid and technically simpler and safer than other mainstream bariatric operations. Leaks or bleeding are rare. The jejunal bypass length is modifiable with the degree of BMI and the MGB has shown durable weight loss and co-morbidity resolution. The single non-obstructing antecolic GJ anastomosis constructed in easy view provides a technically easy option for revision or reversal. The MGB patient should be monitored for possible development of hypoalbuminemia and iron deficiency. The MGB and the OAGB are 
now mainstream in most countries.

\section{Acknowledgement}

The authors thank Prof. Miguel Carbajo (Member of International Committee for the European Accreditation Council for Bariatric Surgery of IFSO), Kuldeepak S. Kular (President of the MGB-OAGB Club) and Robert Rutledge, MD, FACS, for suggestions with this paper.

\section{References}

1. Rutledge R. The mini-gastric bypass: experience with first 1,274 cases. Obes Surg. 2001; 11: 276-280.

2. Rutledge $R$, Walsh TR. Continued excellent results with the mini-gastric bypass: six-year study in 2,410 patients. Obes Surg. 2005; 15: 1304-1308.

3. Lee WJ, Yu PJ, Wang W, Chen TC, Wei PL, Huang MT. Laparoscopic Roux-en-Y versus mini-gastric bypass for the treatment of morbid obesity: a prospective randomized controlled clinical trial. Ann Surg. 2005; 42: 20-28.

4. Rutledge R. Revision of failed gastric banding to mini-gastric bypass. Obes Surg. 2006; 16: 521-523.

5. Noun R, Riachi E, Zeidan S, Abboud B, Chalhoub V, Yazigi A. Mini-gastric bypass by mini-laparotomy: a cost-effective alternative in the laparoscopic era. Obes Surg. 2007; 17: 1482-1486.

6. Chakhtoura G, Zinzindohou F, Ghanem Y, Ruseykin I, Dutranoy JC, Chevallie JM. Primary results of laparoscopic mini-gastric bypass in a French obesitysurgery specialized university hospital. Obes Surg. 2008; 18: 1130-1133.

7. Chevallier JM, Chakhtoura G, Zinzindohoue F. Laparoscopic mini-gastric bypass. In: Deitel M, Gagner M, Dixon JB, editors. Handbook of Obesity Surgery. Toronto: FD-Communications. 2010: 78-84.

8. Piazza L, Ferrara F, Leanza S, Coco D, Sarva S, Bellia A, et al. Laparoscopic mini-gastric bypass: short-term single-institute experience. Updates Surg. 2011; 63: 239-242.

9. Noun R, Skaff J, Riachi E, Daher R, Antoun NA, Nasr M. One thousand consecutive mini-gastric bypass: short and long-term outcome. Obes Surg. 2012; 22: 697-703.

10. Peterko AC, Mazul-Sunko B, Mirosevic G, Bekavac-Beslin M. Combined sleeve gastrectomy and mini-gastric bypass in a new bariatric procedure of mini-gastric bypass and proximal sleeve gastrectomy. Acta Clin Croat. 2013; 52: 316-320.

11. Musella M, Sousa A, Greco F, De Luca M, Manno E, Di Stefano C, et al. The laparoscopic mini-gastric bypass: the Italian experience: outcomes from 974 consecutive cases in a multi-center review. Surg Endosc. 2014; 28: 156-163.

12. Kular KS, Manchanda N, Rutledge R. A 6-year experience with 1,054 minigastric bypasses-first study from Indian subcontinent. Obes Surg. 2014; 24 : 1430-1435.

13. Musella M, Milone M, Gaudioso D, Bianco P, Palumbo R, Bellini M, et al. A decade of bariatric surgery. What have we learned? Outcome in 520 patients from a single institution. Int J Surg. 2014; 12: 183-188.

14. Chevallier JM, Arman GA, Guenzi M, Rau C, Bruzzi M, Beaupel N, et al One thousand single anastomosis (omega loop) gastric bypasses to treat morbid obesity in a 7-year period: outcomes show few complications and good efficacy. Obes Surg. 2015; 25: 951-958.

15. Deitel M. Letter to the editor: bariatric surgery worldwide 2013 revealsa rise in mini gastric bypass. Obes Surg. 2015; 25: 2165.

16. Moszkowicz D, Arienzo R, Khettab I, Rahmi G, Zinzindohoue F, Berger A, et al. Sleeve gastrectomy severe complications: is it always a reasonable surgical option? Obes Surg. 2013; 3: 676-686.

17. Sakran N, Assalia A, Keidar A, Goitein D. Gastrobronchial fistula as a complication of bariatric surgery: a series of 6 cases. Obes Facts. 2012; 5 : 538-545.

18. Gagner M, Deitel M, Erickson AL, Crosby RD. Survey on Laparoscopic
Sleeve Gastrectomy (LSG) at the Fourth International Consensus Summit on Sleeve Gastrectomy. Obes Surg. 2013; 23: 2013-2017.

19. Tolone S, Cristiano S, Savarino E, Lucido FS, Fico DI, Docimo L. Effects of omega-loop bypass on esophagogastric junction function. Surg Obes Relat Dis. 2016; 12: 62-69.

20. Mion F, Tolone S, Garros A, Savarino E, Palascini E, Robert M, et al. Highresolutuon impedance manometry after sleeve gastrectomy: increased intragastric pressure and reflux are frequent events. Obes Surg. 2016; 26: 2449-2456

21. Lee WJ, Wang W, Lee YC, Huang MT, Ser KH, Chen J. Laparoscopic minigastric bypass: experience with tailored bypass limb according to body weight. Obes Surg. 2008; 18: 294-299.

22. Jammu GS, Sharma R. A 7-year clinical audit of 1107 cases comparing sleeve gastrectomy, Roux-en-Y gastric bypass and mini-gastric bypass, to determine an effective and safe bariatric and metabolic procedure. Obes Surg. 2016; 26: 928-932.

23. Peraglie C. Laparoscopic Minigastric Bypass (LMGB) in the super-super obese: outcomes in 16 patients. Obes Surg. 2008; 18: 1126-1129.

24. Rutledge R, Kular KS, Deitel M. Laparoscopic mini-gastric (One-Anastomosis) bypass surgery. Obesity, Bariatric and Metabolic Surgery. Springer. 2016; 415-423.

25. Prasad A. Robotic one anastomosis (omega loop/mini) gastric bypass for morbid obesity. J Robotic Surg. 2014; 8: 371-374.

26. Deitel M, Prasad A, Kular KS, Rutledge R. Report on the Mini-Gastric Bypass Conclave, India. Bariatric News. 2015; 26: 33.

27. Tacchino RM, Greco F, Matera D, Diflumeri G. Single-incision laparoscopic gastric bypass for morbid obesity. Obes Surg. 2010; 20: 1154-1160.

28. Greco F, Tacchino R. lleal food diversion: a simple, powerful and easily revisable and reversible single-anastomosis gastric bypass. Obes Surg. 2015; 25: 680-686.

29. Lee WJ, Lee YC, Ser KH, Chen SC, Su YH. Revisional surgery for laparoscopic minigastric bypass. Surg Obes Relat Dis. 2011; 7: 486-491.

30. Garcia-Caballero M, Carbajo M. One anastomosis gastric bypass: a simple, safe and efficient procedure for treating morbid obesity. Nutr Hosp. 2004; 19: $372-375$.

31. Carbajo MA, Luque-de-Leon E, Jiminez JM, Ortiz-de-Solorzano J, PerezMiranda M, Castro-Alija MJ. Laparoscopic one-anastomosis gastric bypass: technique, results and long-term follow-up in 1200 patients. Obes Surg. 2016.

32. Weiner RA, Theodoridou S, Weiner S. Failure of laparoscopic sleeve gastrectomy-further procedure? Obes Facts. 2011; 1: 42-46

33. Golomb I, Ben David M, Glass A, Kolitz T, Keidar A. Long-term metabolic effects of laparoscopic sleeve gastrectomy. JAMA Surg. 2015; 150: 10511057.

34. Thereaux J, Barsamian C, Bretault M, Dusaussoy H, Lamarque D, Bouillot $\mathrm{JL}$, et al. $\mathrm{pH}$ monitoring of gastro-oesophageal reflux before and after laparoscopic sleeve gastrectomy. Br J Surg. 2016; 103: 399-406.

35. Mason EE, Ito C. Gastric bypass. Ann Surg. 1969; 170: 329-339.

36. Deitel M, Kular KS. Mini-gastric (one-anastomosis) bypass course. Bariatric News. 2014; 22: 8.

37. Peraglie C. Laparoscopic mini-gastric bypass in patients age 60 and older. Surg Endosc. 2016; 30: 38-43.

38. Coblijn UK, Lagarde SM, De Castro SMM, Kuiken SD, Van Wagensveld BA. Symptomatic marginal ulcer disease after Roux-en-Y gastric bypass: incidence, risk factors and management. Obes Surg. 2015; 25: 805-811.

39. Chen MC, Lee YC, Lee WJ, Liu HL, Ser KH. Diet behavior and low hemoglobin level after laparoscopic mini-gastric bypass surgery. Hepatogastroenterology. 2012; 59: 2530-2532.

40. Scozzari G, Trapani R, Toppino M, Morino M. Esophagogastric cancer after bariatric surgery: systematic review of the literature. Surg Obes Relat Dis. 2013; 9: 133-142. 
41. Scheepers AF, Schoon EJ, Nienhuijs SW. Esophageal cancer after sleeve gastrectomy. Surg Obes Relat Dis. 2011; 7: 11-12.

42. Angrisani L, Santonicola A, Iovino P. Gastric cancer: a de novo diagnosis after laparoscopic sleeve gastrectomy. Surg Obes Relat Dis. 2014; 10: 186187

43. Braghetto I, Csendes A. Prevalence of Barrett's esophagus in bariatric patients undergoing sleeve gastrectomy. Obes Surg. 2016; 26: 710-714.

44. Wu CC, Lee WJ, Ser KH, Chen JC, Tsou JJ, Chen SC, et al. Gastric cancer after mini-gastric bypass surgery: a case report. Asian J Endosc Surg. 2013 6: 303-306.

45. Schafer LW, Larson DE, Melton LJ. The risk of gastric carcinoma after surgical treatment for benign ulcer disease: a population-based study in Olmsted County, MN. N Engl J Med.1983; 309: 1210-1213.

46. Luukkonen $P$, Kalima $T$, Kivilaako $E$. Decreased risk of gastric stump carcinoma after partial gastrectomy. Hepatogastroenterol. 1990; 37: 392-394.

47. Bassily R, Smallwood RA, Crotty B. Risk of gastric cancer is not increased after partial gastrectomy. J Gastroenterol Hepatol. 2000; 15: 762-765.

48. Frantz JD, Bretton G, Cartwright ME, Crissman JW, Macklin AW, Maronpo RR. Proliferative lesions of the non-glandular and glandular stomach of rats. In: Guides for Toxicologic Pathology STP/ARP/AFIP, Washington, DC. 1991: 1-20.

49. Christou NV, Look D, MacLean LD. Weight gain after short and long-limb gastric bypass in patients followed for longer than 10 years. Ann Surg. 2006; 244: 734-740.

50. Hsieh T, Zurita L, Grover H, Bennett A, Farrokhyar F, Gmora S, et al. 10-year outcomes of the vertical transected gastric bypass for obesity: a systematic review. Obes Surg. 2014; 24 : 456-461.

51. Padwal R, Klarenbach S, Wiebe N, Birch D, Karmali S, Manns B, et al. Bariatric surgery: a systematic review and network meta-analysis of randomized trials. Obes Rev. 2011; 12: 602-621

52. Lee WJ, Ser KH, Lee YC, Tsou JJ, Chen SC, Chen JC. Laparoscopic Rouxen-Y vs. mini-gastric bypass for the treatment of morbid obesity: a 10-year experience. Obes Surg. 2012; 22: 1827-1834.

53. Disse E, Pasquer A, Espalieu P, Poncet G, Gouillat C, Robert M. Greater weight loss with the omega loop bypass compared to Roux-en-Y gastric bypass: a comparative study. Obes Surg. 2014; 24: 841-846.

54. Kular KS, Manchanda N, Rutledge R. Analysis of the five-year outcomes of sleeve gastrectomy and mini gastric bypass: A report from the Indian subcontinent. Obes Surg. 2014; 24: 1724-1728.

55. Lee WJ, Chong K, Lin YH, Wei JH, Chen SC. Laparoscopic sleeve gastrectomy versus single anastomosis (mini-) gastric bypass for the treatment of type 2 diabetes mellitus: 5-year results of a randomized trial and study of incretin effect. Obes Surg. 2014; 24: 1552-1562.

56. Bruzzi M, Rau C, Voron T, Guenzi M, Berger A, Chevallier JM. Single anastomosis or mini-gastric bypass: long-term results and quality of life after a 5-year follow-up. Surg Obes Relat Dis. 2015; 11: 321-326.

57. Georgiadou D, Sergentanis TN, Nixon A, Diamantis T, Tsigris C, Psaltopoulou T. Efficacy and safety of laparoscopic mini-gastric bypass. A systematic review. Surg Obes Relat Dis. 2014; 10: 984-991

58. Milone M, Lupoli R, Maletta P, Di Minno A, Bianco P, Ambrisoni P, et al. Lipid profile changes in patients undergoing bariatric surgery: a comparative study between sleeve gastrectomy and mini-gastric bypass. Int J Surg. 2015; 14 : 28-32.

59. Milone M, Di Minno MN, Leongito M, Maietta $\mathrm{P}$, Bianco $\mathrm{P}$, Taffuri $\mathrm{C}$, et al. Bariatric surgery and diabetes remission: sleeve gastrectomy or mini-gastric bypass? World J Gastroenterol. 2013; 19: 6590-6597.

60. Musella M, Apers J, Rheinwalt K, Ribeiro R, Manno E, Greco F, et al. Efficacy of bariatric surgery in type 2 diabetes mellitus remission: the role of mini gastric bypass/one anastomosis gastric bypass and sleeve gastrectomy at 1 year of follow-up. A European survey. Obes Surg. 2016; 26: 933-940.

61. Quan Y, Huang A, Ye M, Xu M, Zhuang B, Zhang P, et al. Efficacy of laparoscopic mini gastric bypass for obesity and type 2 diabetes mellitus: a systematic review and meta-analysis. Gastroenterol Res Pract. 2016.

62. Kular SK, Manchanda N, Cheema GK. Seven years of mini-gastric bypass in type II diabetes patients with a body mass index $<35 \mathrm{~kg} / \mathrm{m}^{2}$. Obes Surg. 2016; 26: 1457-1462.

63. Garcia-Caballero M, Valle M, Martinez-Moreno JM, Miralles F, Toval JA Mata JM, et al. Resolution of diabetes mellitus and metabolic syndrome in normal weight 24-29 BMI patients with one anastomosis gastric bypass. Nutr Hosp. 2012; 27: 623-631.

64. Carbajo MA, Jimenez JM, Castro MJ, Ortiz-Solorzano J, Arango A. Outcomes and weight loss, fasting blood glucose and glycosylated hemoglobin in a sample of 415 obese patients, included in the database of the European Accreditation Council for Excellence Centers for Bariatric Surgery with Laparoscopic One Anastomosis Gastric Bypass. Nutr Hosp. 2014; 30: 10321038.

65. Carbajo MA, Vazquez-Pelcastre R, Aparicio-Ponce R, Luque De Lyon E, Jimenez JM, Ortiz-Solarzano J, et al. 12-year old adolescent with super morbid obesity, treated with laparoscopic one anastomosis gastric bypass (LOAGB/BAGUA): A case report after 5-year follow-up. Nutr Hosp. 2015; 31: 2327-2332.
Austin J Surg - Volume 3 Issue 3 - 2016

ISSN : 2381-9030 | www.austinpublishing group.com

Deitel et al. (C) All rights are reserved
Citation: Deitel M, Hargroder D and Peraglie C. Mini-Gastric Bypass for Bariatric Surgery Increasing Worldwide. Austin J Surg. 2016; 3(3): 1092 